\title{
Culturas Juvenis Católicas: aproximações teóricas às performances institucionalizadas
}

Brenda Carranza*

Flávio Munhoz Sofiati**

\section{Resumo}

Com base na pesquisa "As novas configurações da religião no século XXI: um inventário sobre jovens participantes em eventos de massa religiosos", realizada na Jornada Mundial da Juventude (JMJ/Rio Janeiro, 2013), e acompanhada de outros dados, é lastreado o posicionamento dos jovens sobre temáticas em que a Igreja católica tem um parecer definitivo e irredutível. 0 objetivo do texto é o de contrastar a intencionalidade da igreja e seu empenho na realização da JMJ com as posturas dos participantes da JMJ, imersos num processo de reorganização e atualização das crenças e práticas religiosas no meio de um pluralismo secular. A hipótese que orienta a discussão é a de que existe um jogo de negociação entre um alinhamento institucional dos jovens pentecostalizados e uma criativa salvaguarda da sua autonomia pessoal. Sustenta-se que uma análise baseada na categorização de uma juventude alinhada institucionalmente e conceitualizada como cultura juvenil contribui para a formulação de uma sociologia da juventude católica, ainda que tal abordagem se coloque na contramão de outros estudos realizados na mesma direção.

\section{Palavras-chave}

Cultura juvenil. Catolicismo. Pluralismo secular. Alinhamento institucional.

\section{Abstract}

Based on the research "The New Configurations of Religion in the 21st Century: An Inventory on Young People Who Participate in Religious Mass Events", carried out during the World Youth Day (WYD/ Rio de Janeiro, 2013), and based on other data, the youth's positioning is ballasted regarding themes in which the Catholic church has a definite and irreducible judgement. The

\footnotetext{
* Brenda Carranza é doutora em Ciências Sociais pela Universidade Estadual de Campinas; e professora pesquisadora da Pontifícia Universidade Católica de Campinas (PUC-Campinas). E-mail: brenda_poveda@terra.com.br .

** Flávio Munhoz Sofiati é doutor em Sociologia pela Universidade de São Paulo; e professor associado da Universidade Federal de Goiás. E-mail: sofiati@gmail.com .
} 
goal of this work is to contrast the church's intentionality and its effort in accomplishing the WYD with the postures of the WYD's participants, immersed in a process of recognition and actualization of religious beliefs and practices among a secular pluralism. The hypothesis that guides the discussion is that there is a negotiating game between an institutional alignment of Pentecostal young people and a creative safeguard of their personal autonomy. It is supported that an analysis based on the categorization of a youth institutionally aligned and conceptualized as youth culture contributes to the formulation of a Catholic youth sociology, even if this approach is in the contraflow of other studies carried out in the same direction.

\section{Keywords}

Youth culture. Catholicism. Secular pluralism. Institutional Alignment.

\section{Introdução}

Para analisar a juventude católica, partimos do pressuposto advogado por Peter Berger (2017), para o qual o pluralismo não se reduz apenas à quebra do monopólio de uma instituição religiosa sobre o campo religioso ou a perda de influência das instituições tradicionais sobre a sociedade, isto é, o declínio religioso. Para ele, o pluralismo consiste nas diversas formas de assimilar religiosamente os pressupostos seculares que dominam tanto os indivíduos quanto as instituições, o que inclui as religiosas.

Não se trata de renegar o paradigma da secularização (BERGER, 2017, p. 9-17) - que continua a ser uma interface analítica entre a modernidade e a religião - ou alardear uma dessecularização (BERGER, 2001) que releve a diferenciação das esferas sociais, ou ainda contrapor secularização ao pluralismo. Para o autor, significa se render ao fato de o mundo moderno continuar a ser muito religioso, e a secularização ter sido acompanhada de um movimento de vitalidade e revigoramento desse discurso. É reconhecer que as crenças e práticas religiosas permanecem presentes na vida das pessoas e se reorganizam a partir de novas instituições e pressupostos.

Nossa hipótese neste trabalho é que na juventude católica podem-se identificar tais postulados que nutrem sistemas de culturas juvenis e, entre esses últimos, predomina uma juventude alinhada institucionalmente, que tende a ser hegemônica. No esforço de tipificar essa juventude católica, atentamos para certa oscilação dos jovens entre uma autonomia relativa perante a bagagem institucional e um alinhamento criativo com os ensinamentos e doutrinas tradicionais. Intuição que podemos rastrear com 
o auxílio da pesquisa, entre outras, "As novas configurações da religião no século XXI: um inventário sobre jovens participantes em eventos de massa religiosos", coordenada por Paulo Gracino (IUPERJ) e Cecília Mariz (UERJ), financiada pela Fundação de Apoio à Pesquisa do Estado do Rio de Janeiro - FAPERJ, e realizada à época da Jornada Mundial da Juventude (JMJ), ocorrida no Rio de Janeiro em 2013, doravante citada: pesquisa FAPERJ .

Evidentemente que o pluralismo interno do catolicismo não é uma novidade, e nas juventudes organizadas não seria diferente, porém quais dispositivos são acionados pela Instituição para validar crenças e práticas? Nesse sentido, intentamos saber quais os mecanismos que esses jovens deflagram para negociar, ou não, sua autonomia pessoal configurada a partir de um pluralismo secular. Nos termos de Berger, trata-se de capturar como "[...] na vida de muitos crentes comuns [eles] conseguem ser tanto seculares quanto religiosos. Eu diria que são essas pessoas que realizam o ato de equilíbrio cognitivo prototípico da modernidade" (2017, p.15).

Nosso propósito neste texto é o de sugerir a categorização da cultura juvenil a partir de uma juventude alinhada aos interesses institucionalizados como elementos para, de uma parte, problematizar a compreensão da realidade juvenil católica no Brasil contemporâneo, de outro lado, somar esforços na constituição de uma sociologia da juventude católica, exercício sugerido por Michael Löwy (apud CAMURÇA, 2015, p. 19). Subjaze a esse propósito a conviç̧ão de que a conceitualização da juventude, entendida como categoria sociológica pertinente, se insere num escopo conceitual mais amplo na análise do catolicismo, qual seja a pentecostalização do cristianismo, entendida essa como a precipitação do estilo pentecostal para o cerne da sociedade, influenciando tanto as instituições cristãs quanto as suas interações com o campo religioso e social (CARRANZA, 2015, p. 72).

A seguir, indagamos sobre as motivações institucionais da JMJ eo contexto da sua realização no Rio de Janeiro. Na continuidade, apresentamos alguns dos posicionamentos que a juventude pesquisada nas Jornadas manifesta em torno de temáticas polêmicas sobre moralidade sexual, em que a Igreja Católica tem uma definição doutrinal irredutível. Logo, dedicamos uma parte deste texto a discutir a relevância da noção de cultural juvenil para, finalmente, esboçar algumas considerações que contribuam com a discussão mais alargada para uma sociologia da juventude católica no Brasil. 


\section{0 porto seguro da juventude católica}

Na década dos anos 1980, entra na pauta do debate internacional a condição juvenil: a ONU proclama o ano internacional da Juventude (1980) e o papa João Paulo II idealiza as Jornadas Mundiais da Juventude (1986). Desde então até 2016 foram 32 JMJ. A penúltima edição da Jornada, realizada no Rio (2013), contou com a presença do recém-eleito papa Francisco, o cardeal argentino Jorge Bergoglio. Ele foi recebido 3,7 milhões de pessoas, $60 \mathrm{mil}$ voluntários, 180 mil peregrinos. A todos eles, Francisco dirigiu discursos, homilias e mensagens, dentre as 21 intervenções proferidas, no meio de inúmeras atividades catequéticas (300 proferidas por bispos em 26 línguas), celebrações de sacramentos, missas, vigílias, via-sacra, festivais gospelcatólico e espaços alternativos de discussão social e ecumênica.

Desde seus primórdios, a JMJ constituiu-se uma iniciativa sistemática de reativar a memória de pertencimento da juventude católica à Igreja, mobilização descentralizada de recursos, propiciadora de experiências emotivas de peregrinação, voluntariado, hospitalidade, e troca de vivências entre jovens. Para a hierarquia transformou-se na ocasião ímpar de aglutinar esforços em prol de atrair os jovens para participar da vida cotidiana da Igreja (reinstitucionalização), entendida como tentativa de dar visibilidade ao catolicismo, incentivar a organização das igrejas locais, inculcar, em escala mundial, o referencial doutrinal e teológico e sua visão de juventude católica.

Nas Jornadas são reelaboradas temáticas e assuntos tratados em outras Jornadas, em documentos e em papas anteriores, caracterizando-se as abordagens por sua linguagem autorreferenciada. Nesses eventos explicitase a proposta católica de universalizar as relações sociais que constituem uma cultura institucional própria, desenvolver formas específicas de compreender o cristianismo em sua relação com o mundo secular e outras religiões. Sob a máxima "civilização do amor", que acompanha todas as Jornadas, condensa-se o princípio totalizador da verdade da qual a Igreja Católica é portadora e na qual os peregrinos das Jornadas podem encontrar as certezas que inspirem sua vida cotidiana (MARIZ; CARRANZA, 2017, p.74).

Papa Francisco dirige aos voluntários o seguinte encorajamento: “ $\mathrm{Na}$ cultura do provisório, do relativo, muitos pregam que o importante é 'curtir' o momento (...) eu peço que vocês sejam revolucionários, eu peço que vocês 
vão contra a corrente (...) se rebelem contra esta cultura do provisório"1. Note-se a atualização e o afinamento com uma das percepções sobre a juventude dos anos 1980 e o incentivo a uma revolução comportamental nos moldes funcionais da própria sociedade capitalista.

Em geral, as JMJ tendem a exercer uma dupla função: promover momentos de ressignificação da vivência religiosa e reforçar determinadas crenças nos participantes. Constituem-se momentos fundamentais para a Igreja Católica recuperar seu ímpeto pela evangelização da juventude, tentar convencer os jovens de que o catolicismo é ainda um porto seguro, mobilização que responde à constante preocupação da instituição de retomar o gap geracional, que tende a ser angustiante por se tratar da retransmissão da fé e da experiência religiosa, muitas vezes medida nas práticas e adesão institucional.

No Brasil essa preocupação será justificada perante dados do Pew Research Center, publicados previamente à JMJ/RJ. O estudo Brazil's Changing Religius Landscape ${ }^{2}$ constatou profunda mudança geracional que contribuí para a diminuição do número de católicos no país. A partir do Censo de 2010, os protestantes representam mais de um quinto (22\%) dos brasileiros com idades entre 15-29, em comparação com $17 \%$ dos católicos com 70 ou mais anos. Os católicos tendem a ser mais velhos e vivem em áreas rurais, enquanto os protestantes são ligeiramente mais jovens e a maioria vive em áreas urbanas.

Mais, em 20 anos os católicos brasileiros passaram de 83,8\% para $64,4 \%$ da população brasileira. Neste contexto, a disputa por jovens é essencial, mesmo porque o caso dos católicos tem sido de formar jovens para mais tarde serem absorvidos pelas denominações evangélicas (BRANDÃO, 2013, p. 93; PEW RESEARCH CENTER)3. Todavia, parece não ser mais possível identificar automaticamente o "ser" católico com o "ser" brasileiro, embora seja ainda a religião autodeclarada da maioria dos brasileiros (123

\footnotetext{
1 Disponível em: <https://w2.vatican.va/content/francesco/pt/speeches/2013/july/ documents/papa-francesco_20130728_gmg-rio-volontari.html>. Acesso em 14 de abril de 2018.

2 Disponível em: <http://www.pewforum.org/2013/07/18/brazils-changing-religiouslandscape $>$. Acesso em 18 de março de 2018.

3 Disponível em: <http://www.pewforum.org/2013/07/18/brazils-changing-religiouslandscape>. Acesso em 18 março de 2018.
} 
milhões), seja o país que tem mais católicos romanos que em qualquer outro do mundo ${ }^{4}$, e seja a maior e mais importante instituição religiosa do Brasil.

Evidenciada a problemática estrutural do catolicismo, compreende-se que a reaproximação da Igreja Católica com os jovens e fiéis é essencial. Certamente, eventos multitudinários do porte da JMJ concretizam as aspirações institucionais, ainda que transcenda a intencionalidade de seus idealizadores, transformando-se num evento público, percebido como um palco erguido no meio do espaço público - físico e virtual - em que se revelam sentimentos, ideias, afetos, narrativas em construção de legitimidade, posições ideológicas e políticas, às vezes antagônicas, mas unidas por um catalizador comum. Em termos simbólicos, os eventos públicos conectam com inúmeras cadeias de significados que falam de contextos e conteúdos latentes daquilo que não é claramente explicitado, porém, quando capturado, permite mapear as tendências dos grupos aí representados (SILVA, 2017, p. 3).

A JMJ do Rio como evento público foi para além das manifestações puramente religiosas e reverberou o clima conjuntural das manifestações sociais de junho de 2013, cuja principal protagonista seria a juventude. Da parte institucional, o papa teria recebido dos bispos brasileiros um informe no qual se esboçou a juventude que o esperaria no Brasil: menos individualista e mais sensível às questões sociais ${ }^{5}$. Munido de tais informações, um duplo desafio se apresentaria para o papa Francisco em sua primeira viagem internacional: testar seu estilo pastoral, marcado por proximidade, simplicidade, postura política de questionamento e denúncia; e oportunizar sua popularidade para ser revertida em termos de adesão institucional dos peregrinos. Com isso, seus pronunciamentos enfatizaram mais um discurso social e driblaram veredas repetitivas da moralidade católica, traçando linhas simbólicas de reposicionamento sobre questões de diversidade sexual e direitos reprodutivos sem aparentes colisões doutrinais (MARIZ; CARRANZA, 2017, p. 88).

\footnotetext{
4 Disponível em: <http://www.pewforum.org/2013/07/18/brazils-changing-religiouslandscape>. Acesso em 18 de março de 2018.

${ }^{5}$ Disponível em: <http://www.istoe.com.br/reportagens/314126_A+NOVA+JUVENTUDE+ CATOLICA+BRASILEIRA\#.UeRQekVXr2s.> . Edição n. 2278. / 12.Jul.13 - 20:40 . Acesso em 16 de julho de 2013.
} 
Mesmo assim, eventos públicos com dimensões multitudinárias do porte da JMJ nos permitem questionar: em que medida os propósitos e esforços institucionais coincidem com os objetivos dos jovens peregrinos e participantes convocados no Rio? A popularidade e o carisma do Papa revertem no seguimento de suas ideias, no respeito aos preceitos católicos e na adesão incondicional a seus postulados doutrinais? Estudos sobre a juventude católica (SOFIATI, 2011, 2012) apontam que os dogmas católicos são desconsiderados ou mesmo reconfigurados conforme a realidade dos agrupamentos juvenis católicos espalhados por todo o país.

Na continuação nos detemos no público juvenil da JMJ, o que pensam e expressam sobre assuntos temáticos, polêmicas da teologia moral católica, cuja definição vem sendo apresentada nos últimos papados como valores irrenunciáveis. Tais depoimentos revelam uma negociação criativa daqueles que, sem deixar de ser modernos, se alinham institucionalmente.

\section{Modernos e alinhados}

A riqueza dos dados coletados nas 974 entrevistas da pesquisa FAPERJ permite refinar o perfil católico do público inscrito na JMJ/RJ-20136. A composição da amostra nos aproxima do perfil desse público: 51,7\% masculino e $48,3 \%$ feminino; a idade concentrou-se entre os 21 a 25 anos (30\%), seguida dos jovens de 18 a $20(27,4 \%)$; menores de 16 e 17 anos somaram 19,5\%; apenas 6,1\% até 15 anos, e maiores de 26 anos $17 \%$. A escolaridade desses jovens surpreende com 53\% de ensino superior, 20,3\% ensino médio e sem completar $26,1 \%$. Ao serem questionados se tinham participado de outras Jornadas, $17,6 \%$ já se tinham deslocado a outros países, dessa porcentagem, 3,8\% eram brasileiros.

Lastreamos a identidade religiosa da juventude, assim: 95,6\% sempre foram católicos, informando que $34,2 \%$ se consideram atualmente católicos praticantes e $62,4 \%$ reconhecem sempre ter sido, apenas $2,2 \%$ declararam nunca terem sido praticantes. Como prática que se traduz numa frequência elevada nas atividades na igreja: $60 \%$ declaram frequentar mais de uma vez

\footnotetext{
${ }^{6}$ Os dados da pesquisa são o universo de jovens inscritos na Jornada em julho/2013, a técnica da coleta foi de entrevistas presenciais em fluxo, o período colhido foi de 23 de julho a 11 de agosto de 2013, realizada uma amostra de 974 entrevistas, sendo a margem de erro: +/- 3,1\%.
} 
por semana; $30,7 \%$ uma vez por semana, caindo para $3,1 \%$ os que a cada mês comparecem, $2,6 \%$ quinzenalmente e $2 \%$ só aparecem nas festividades. Assiduidade de $63,4 \%$ da juventude em algum grupo da igreja, entre eles: Grupo de jovens 12,5\%, Renovação Carismática Católica 12\%; Pastoral 9,1\%; Neocatumenato 6,1\%; Regnum Christi (1,6\%), Opus Deis 1,5\%, Schoenstatt $1 \%$, Salesianos 1,1\%; do restante de informantes não se tem informação. À pergunta por meio de qual entidade se inscreveu na Jornada, $46 \%$ dos jovens respondem que pela paróquia; 34,7\% movimento de jovens; 9,7\% participaram por conta própria; e 4,6\% indicam que a entidade foi escola ou colégio.

É fácil deduzir que o público pesquisado mantêm laços orgânicos com a Igreja e certa afinidade eletiva por ela, de maneira que, quando solicitado opinar sobre a afirmação: a Igreja católica é a verdadeira igreja de Cristo, $63 \%$ concordaram totalmente, $25 \%$ parcialmente e apenas 1,6\% discordou totalmente. A Jornada parece ser um evento da Igreja para Igreja, cujo epicentro é seu magistério e o papa seu porta-voz. No caso da JMJ/RJ, de acordo com o Instituto DataFolha ${ }^{7}$, para $82 \%$ dos jovens o motivo principal de estarem na Jornada foi ver o recém-eleito papa Francisco.

Esse público assíduo frequentador da Igreja Católica, diversificado em sua inserção eclesial, firmado na veracidade da Igreja e se reconhecendo nela, parece não coincidir com os ensinamentos do magistério e sua doutrina. Destacamos alguns dos itens da pesquisa FAPERJ para capturar o posicionamento dos jovens acerca de moralidade sexual, concepção familiar e questões de gênero. Tal postura argumenta nossa hipótese sobre a existência de mecanismos de negociação que a juventude desencadeia perante a moralidade católica. Os pesquisados são solicitados a manifestar gradativamente sua concordância ou discordância, numa avaliação valorativa de 10 (total aprovação) a 0 (total desaprovação), portanto, quanto mais próximo de zero, maior desaprovação.

No que refere à temática da prática sexual, as apreciações se posicionam em relação ao uso de contraceptivos e da camisinha. Entre os pesquisados,

\footnotetext{
7 Amostra de 1,279 entrevistados num universo de 865 mil participantes. Metodologia: contagem de densidade do público e entrevista de opinião. Pesquisa realizada no evento de Copacabana no dia 25 de jul. 2013. Disponível em: <http://g1.globo.com/jornal-nacional/ noticia/2013/07/ pesquisa-mostra-opiniao-de-peregrinos-da-jmj-sobre-habitos-condenadospela-igreja-catolica.html>. Acesso em 7 de julho de 2013.
} 
o uso de contraceptivos alcança uma média de 4,31. Apurada a situação em que seria aceitável seu uso, 33,6\% dos jovens não aceitam o seu uso em nenhuma situação; $21,5 \%$ só em caso de doença de parceiro; $13,3 \%$ casal com muitos filhos; $6,4 \%$ dificuldade financeira. Já para o uso da caminha a média se eleva para 5,34 a situação em que considera aceitável seu uso. A percentagem maior recai nas razões de saúde; quando o parceiro tem DST, 2,91\%; 26,6\% não aceitam em situação alguma. Dada a procedência e os laços orgânicos dos pesquisados, o posicionamento dos inscritos é moderado, ainda que $53 \%$ possuam ensino superior e oscilem entre 20 e 25 anos. Mesmo assim, existem parcelas relativamente significativas que se afastam desse perfil, pois 19,3\% e $28 \%$ aceitam o uso de contraceptivos e de camisinha em qualquer situação.

A tendência se repete num público ampliado que, mesmo sendo $95 \%$ autodeclarados católicos, pronuncia-se perante o DataFolha da seguinte maneira: $65 \%$ defendem o uso de camisinha, 31\% dizem estar contra e 3\% são indiferentes ou não souberam responder. Sondados sobre qual deveria ser a posição do papa, 55\% dos entrevistados acham que o papa deveria orientar que a Igreja fosse a favor dessa prática. Já sobre o uso da pílula anticoncepcional para evitar gravidez, 53\% são favoráveis, $41 \%$ contrários, $3 \%$ são indiferentes e $3 \%$ não souberam responder. Tanto a sondagem da pesquisa FAPERJ quanto do Data Folha mostram que no quesito prática sexual, que envolve decisões mais pessoais e íntimas, os jovens tendem a flexibilizar os ensinamentos doutrinais.

O contrário acontece quando se trata do aborto, que registra um forte alinhamento institucional em relação às orientações da Igreja, claras e irredutíveis em prol da vida do feto em quaisquer circunstâncias. Assim, a desaprovação dos jovens mesura-se na média 1,6; para 54\% não é aceitável em situação nenhuma; 25\% aceitam em caso de estupro; 19,2\% concordam quando há risco de morte da mãe e 6,2\% do feto. Qualquer situação, grávida muito jovem e situação financeira registram, respectivamente: 1,5\%, 1,5\%, e $0,5 \%$.

A mesma tendência em relação ao posicionamento da Igreja será encontrada em caso de união homoafetiva, cuja média de rejeição é de 2,61 e de 2,43 na adoção de criança. A porcentagem de rejeição da adoção em qualquer situação é de $64 \%$; apenas $6,3 \%$ se for criança abandonada e 1,4\% se não houver outro meio, porém uma parcela de 15,3\% aprova a adoção em qualquer situação, o que implica indiretamente a aceitação do relacionamento homossexual. Outra brecha é revelada ao ser solicitada a 
concordância sobre relações antes do casamento, pois 34,6\% concordam totalmente ou parcialmente; em somatória similar, o casal morar junto antes do casamento, 43,9\% manifestam sua concordância parcial ou total.

Abordada a posição sobre o divórcio, a média de aceitação foi de 3,28; os motivos para essa aceitação para $44,3 \%$ são a violência doméstica; falta de amor 18,8\%; infidelidade 15,8\%; qualquer situação $0,3 \%$, e $29,7 \%$ não aceitam sob nenhuma situação. A esse dado conservador se contrapõe a rejeição da visão de família patriarcal, quando 62,7\% discordam parcial e totalmente da afirmação: cabe ao homem ganhar dinheiro e à mulher cuidar da família em contraposição a $25,8 \%$ que concorda total ou parcialmente. Também há uma forte rejeição a reduzir a mulher à esfera doméstica, pois $70 \%$ discordam parcial ou totalmente da afirmação: a vida familiar é prejudicada quando a mulher trabalha. Tal visão marca descompasso com a insistente tendência de relegar o papel da mulher à circunscrição doméstica, por parte de determinados setores religiosos.

Porém, o realinhamento institucional em questão de gênero reaparece quando se trata da esfera eclesial para a qual o empoderamento feminino continua a estar fora de cogitação. É o que manifestam $52 \%$ dos entrevistados que discordam parcial ou totalmente da sentença: as mulheres deveriam poder exercer o sacerdócio na Igreja Católica, 35,8\% aprovam parcial ou totalmente e $10 \%$ são indiferentes. Contrariamente à postura dos jovens, em pesquisa encomendada junto à população em geral, o IBOPE registrou que $62 \%$ dos entrevistados aprovam maciçamente a ordenação de mulheres ${ }^{8}$.

Os dados nos mostram a juventude católica imersa num jogo de negociação quando os temas atingem suas práticas pessoais, afinamentos parciais sobre o papel da mulher e alinhamentos institucionais quando os temas abrangem opções éticas em torno de valores consolidados como os da família e as relações homoafetivas. Égide temática sob a perspectiva de defesa dos direitos reprodutivos e o reconhecimento da legitimidade da diversidade sexual, os movimentos sociais e minorias sexuais nos últimos anos vêm colocando na pauta de discussão social e legislativa (VITALCUNHA; LOPES, 2017, p. 7-9).

\footnotetext{
${ }^{8}$ Pesquisa de opinião encomendada pela ONG Católicas pelo Direito a Decidir (CDD) ao IBOPE, que ouviu 4 mil brasileiros, no mês de julho de 2013. Disponível em: <http://www. ihu.unisinos.br/noticias/522138-jovens-catolicos-tem-visoes-opostas-as-da-igreja-diz-ibope>. Acesso em: 25.jul.2013.
} 
Embora a pessoa de Francisco tenha exercido forte magnetismo sobre os participantes da JMJ/RJ, o que não difere de João Paulo II nas JMJ anteriores, essa atração não impede o distanciamento vital dos jovens das propostas doutrinais, como observado nas parcelas dissonantes no uso de contraceptivos e relação homoafetiva. A figura do papa e a mensagem doutrinal da qual é portador emergem como duas instâncias que não se misturam, acomodando-se na subjetividade e no pertencimento religioso dos peregrinos. Assuntos referentes à autonomia pessoal são atravessados pela escolha própria e encapsulados nas decisões íntimas, fora do controle institucional, postura liberal afinada com a cultura moderna do self e a cultura secular que não conflita com o pertencimento e a assiduidade à Igreja, antes bem, são coexistentes.

De acordo com Hervieu-Léger (apud CAMURÇA, 2015, p. 21), essa autonomia pessoal do jovem traz um novo sentido à sua adesão institucional, o que representa uma maior autonomização relativa ao catolicismo institucional, redundando, segundo a autora, no enfraquecimento da estrutura eclesiástica ao perder adesão a seu corpo doutrinal.

No entanto, se essa autonomia pessoal, relegada à intimidade da prática sexual dos participantes da JMJ/RJ que poderia enfraquecer a Instituição em determinados aspectos, antes bem parece equilibrar a adesão institucional em outros, tal o caso do aborto, a posição sobre assuntos relativos às questões da homoafetividade e às práticas institucionais que envolvem questões de gênero na vida sacerdotal. Nesses aspectos, os jovens peregrinos mostramse alinhados aos ensinamentos da Igreja, de maneira que a postura de autonomia pessoal reflete uma subjetividade configurada nos valores modernos e práticas contemporâneas. A segunda postura, o alinhamento institucional, espelha certa acomodação doutrinal à visão da instituição religiosa, conferindo coerência com a identidade religiosa assumida. Se para Hervieu-Léger são posturas excludentes, para a juventude da JMJ/RJ são concomitantes, sendo, simultaneamente, jovens católicos modernos e alinhados institucionalmente.

Dois aspectos parecem confluir nessa identidade que a nosso ver torna a juventude moderna e alinhada institucionalmente: de um lado, o movimento da juventude que reage criativamente à proposta doutrinal, e, do outro lado, o movimento que a Igreja como instância definidora se propõe a realizar. No primeiro, como analisado, os jovens mantêm um jogo de distanciamento cauteloso que preserva suas opções pessoais negociando uma adesão não incondicional aos propósitos institucionais. 
O segundo aspecto é o papel que as instituições possuem de configurarem-se como instâncias definidoras, pois, de acordo com Kerbauy (2005, p. 196-199), ao analisarem a interação entre o Estado e a juventude, essas instituições sobrepõem seus interesses específicos ao estabelecerem processos e traçarem estratégias para perseguir seus objetivos. Nesse sentido, consideramos que a Igreja Católica se constitui instância definidora enquanto, desde o epicentro eclesiástico com seus inúmeros organismos, promove processos e estratégias junto à juventude, visando a incluir no seu horizonte moral e incentivando a adesão institucional dos jovens.

Sem dúvida que essa capacidade de instância definidora da Igreja é recriada junto à juventude em cada JMJ que é arquitetada. As Jornadas detonam inúmeros modos de participação dos jovens como protagonistas da ação, revigorando ad intra eclesia vínculos institucionais da juventude participante. Consequentemente, o perfil dos jovens pesquisados na JMJ/ RJ é o de uma juventude com forte referência institucional, ora por sua procedência de participação ativa na Igreja, ora por seu alinhamento, em determinadas temáticas, ao horizonte moral do catolicismo romano. A presença dessa juventude confirma a capacidade da Igreja de ser uma instância definidora que amplia seus mecanismos de adesão institucional.

Se é certo que esse alinhamento institucional da juventude pode nos aproximar de uma compreensão de como operam mutuamente igreja e juventude católica, também é certo que se corre o risco de esconder a multiplicidade de jovens, grupos juvenis, juventudes que a integram, ofuscando o princípio de pluralidade na unicidade católica que viemos sustentando. É sobre as diversas culturas juvenis que a seguir nos debruçamos.

\section{Dissonantes e plurais}

“O jovem fiel que receberá o papa no Brasil não se dedica mais só à espiritualidade. Ele defende uma agenda social, quer acabar com a pobreza e discute tabus", essa é a chamada da reportagem "A nova juventude católica brasileira", da Revista Isto É que circulou uma semana antes da JMJ/RJ9.

\footnotetext{
${ }^{9}$ Disponível em: http://www.istoe.com.br/reportagens/314126_A+NOVA+JUVENTUDE+C ATOLICA+BRASILEIRA\#.UeRQekVXr2s. Edição 2278. Acesso em 15 de julho de 2013.
} 
A reportagem sintoniza a caracterização de uma juventude católica menos individualista e mais social que o Papa teria recebido dos bispos brasileiros, já mencionada.

A reportagem discorre sobre a diversidade juvenil do catolicismo nos seguintes termos: "Atualmente, o jovem católico que quer transformar a sociedade está ligado à Pastoral da Juventude (PJ), majoritariamente, e também às Comunidades Eclesiais de Base (CEBs)"10. A revista contrapõe a essa juventude, tida historicamente como da ala progressista, uma outra juventude de viés espiritual e intimista, alocada na ala conservadora. Mas essa última juventude, segundo a revista, estaria dando lugar à primeira, ainda que socialmente " [as] CEBs eram o único espaço viável para quem tinha uma ação política e social entre os anos 1960 e 1980, mas perderam importância nos dois últimos pontificados"11.

Avançamos na conceitualização da juventude católica que integrou a JMJ/RJ. Partimos de uma outra perspectiva que quebra com tipologias que engessam a vitalidade da diversidade interna da juventude que, como vimos, ora se alinha institucionalmente ora se distancia ideologicamente da Igreja, mas sem perder seus laços orgânicos com ela. Essa abordagem assume a necessidade de compreender a juventude como categoria sociologicamente pertinente nas análises religiosas e de integrar argumentos, muitas vezes contrapostos, como os da heterogeneidade e efemeridade da condição juvenil (GALLAND, 2009, pp. 03-07).

Nossa análise sobre a juventude católica brasileira considera os estudos de José Machado Pais acerca das culturas juvenis que formulam esse conceito ao considerar os "modos de agir dos jovens no interior dos ritmos da vida cotidiana" (2003, p. 72-75). Na sua sociologia da juventude, ele examina os vínculos entre trajetórias individuais e estruturas sociais e defende que a chave para entender a maneira como os jovens constroem suas relações societárias está centrada na realização dessas "culturas juvenis" compreendidas como "práticas sociais". Entendemos que a juventude

${ }_{10}$ Disponível em: <http://www.istoe.com.br/reportagens/314126_A+NOVA+JUVENTUDE +CATOLICA+BRASILEIRA\#.UeRQekVXr2s> Edição: 2278 | 12.Jul.13 - 20:40. Acesso em 15 julho de 2013.

${ }^{11}$ Disponível em: <http://www.istoe.com.br/reportagens/314126_A+NOVA+JUVENTUDE +CATOLICA+BRASILEIRA\#.UeRQekVXr2s> Edição: 2278 | 12.Jul.13 - 20:40. Acesso em 15 de julho de 2013. 
católica também faz parte desse cenário composto por diversificadas culturas juvenis que desenvolvem novas práticas sociais em seus contextos específicos e nos propomos a estudar como esse processo se estabelece no interior da instituição católica.

Pais (2006, p. 8), inspirado nos escritos de Baudelaire, defende que os cotidianos juvenis se tornaram um "culto da sensação multiplicada", sendo que as estruturas sociais fluidas do mundo contemporâneo tornaram a vida juvenil marcada por inconstâncias, flutuações, descontinuidades e reversibilidades. O autor chama isso de metáfora do ioiô no qual: "Os jovens tendem a tudo relativizar [visto que] Há ritualizações associadas aos afetos e à sexualidade que produzem, entre os jovens, uma mediação entre desejos, angústias e desilusões" (PAIS, 2006, p. 9). Em outros estudos temos assinalado como essas sensações podem ser identificadas nos jovens católicos carismáticos, ao participarem das chamadas Cristotecas, em que são fusionados lazer, segurança e espiritualidade, num misto de boate-bar (CARRANZA, 2014; SOFIATI, 2011).

A condição juvenil contemporânea caracteriza-se por contratempos, tornando-se um "cabo de tormentas" o processo de passagem para a vida adulta (PAIS, 2006, p.11). Por isso, os projetos de vida tendem a se orientar fortemente para o presente, considerando que o futuro é repleto de incertezas e fracassa em oferecer possibilidades concretas de vida com segurança e estabilidade. Pais (2006, p. 10) considera, inclusive, que são projetos curtos cujos objetivos nem sempre são alcançados

Em nossa concepção, a juventude católica também é afetada por esse contexto, principalmente quando inserimos a temática das novas tecnologias de comunicação. A provisoriedade de permanência e rotatividade é um dos elementos da realidade que retrata essa situação entre os católicos, haja vista os participantes nos grupos de jovens paroquiais, os grupos de oração carismáticos e até mesmo algumas novas formas de agregação religiosa, advindas da espiritualidade da Renovação Carismática Católica (RCC), chamadas de Novas Comunidades católicas. Ao resolver os seus principais problemas de aflição, o jovem segue sua vida em busca de novas formas de experiências dentro ou fora do universo religioso (SOFIATI, 2011, p. 223), como também sacraliza esse universo através dos barzinhos de Jesus ou, no caso da JMJ/RJ, as performances religiosas por meio do Flash Mob e festival de música, nos quais a RCC consagrou seu estilo gospel-católico (CARRANZA, 2013, p. 31).

Conforme Pais, "é importante desvendar as sensibilidades 
performativas das culturas juvenis em vez de nos aprisionarmos a modelos prescritivos com os quais os jovens já não se identificam" (2006, p. 13). Nesse sentido, inserimos a noção de culturas juvenis como ferramenta para entender os jovens na contemporaneidade, principalmente em sua vertente católica. Tais culturas juvenis são socializações, expressividades, performances cotidianas produzidas pelos próprios jovens ou assinados a eles. "Por culturas juvenis, em sentido lato, pode entender-se o sistema de valores socialmente atribuídos à juventude (tomada como conjunto referido a uma fase da vida), isto é, valores a que aderirão jovens de diferentes meios e condições sociais" (PAIS, 2003, p. 69). Conforme o autor: "[...] as culturas juvenis são vincadamente performativas porque, na realidade, os jovens nem sempre se enquadram nas culturas prescritivas que a sociedade lhes impõe" (PAIS, 2006, p. 7).

No caso da juventude católica, principal público participante da JMJ/RJ, é importante destacar que há em sua configuração diferentes sensibilidades do modo de ser católico. Faz-se necessário considerar a diversidade de culturas juvenis no catolicismo brasileiro em consideração às suas variações que dão sentido aos catolicismos no país. Destacamos quatro agrupamentos importantes, pensados na perspectiva das tendências orgânicas do catolicismo (SOFIATI, 2011, 2012), e dentro deles inserimos a lógica das culturas juvenis.

O primeiro grupo é chamado de Tradicionalista e é representado, por exemplo, pelos Arautos do Evangelho. Originados no Brasil, aprovados pelo Vaticano em 2011, o movimento congrega um número significativo de jovens, predominantemente celibatários dedicados integralmente à religião. Os Arautos se consideram um instrumento de santidade da Igreja ao praticar o Evangelho em toda a sua "pureza fascinante", sendo que sua espiritualidade é alicerçada na "Eucaristia, em Maria e no Papa". Mais, os tradicionalistas são restritivos no que concerne ao diálogo com a modernidade e formam uma cultura juvenil católica que defende o "resgate de práticas rituais e de costumes medievais" (COSTA, 2014, p. 69).

O segundo grupo, chamado de Reformista, é composto basicamente pelos agrupamentos juvenis formados em torno das escolas católicas ou confessionais, mantidas por congregações religiosas. Os Maristas e Salesianos trabalham diretamente com educação e são os principais representantes dessa vertente católica que defende os direitos humanos e trabalha com ênfase na prática sociocaritativa. Os reformistas estão voltados para o ensino religioso nas escolas, na articulação entre fé e razão, 
em vistas de enfatizar a dimensão humana e social da religião (SOFIATI, 2012). Mas, o principal tema que norteia sua atuação é de fato a educação cristã de crianças e jovens e formação de quadros católicos para assumir postos de poder na sociedade. É a tese da educação católica influenciando as elites dirigentes do país, mesmo que, em alguns casos como os Maristas, haja muitas obras sociais voltadas para a juventude empobrecida (DULLO, 2016). As culturas juvenis cultivadas nessa tendência católica tendem a ter um diálogo mais profícuo com a modernidade em comparação com a tendência anterior.

O terceiro grupo, chamado de Radical, é integrado predominantemente pelas pastorais sociais e pastorais dajuventude. São os adeptos da perspectiva da Teologia da Libertação, dos ideais católicos das Comunidades Eclesiais de Base. Trata-se de uma tendência mais social do catolicismo, que atua em sintonia com os movimentos sociais. Como exemplo, destaca-se a Pastoral da Juventude do Meio Popular, que atua na formação/evangelização de jovens das periferias das grandes cidades. Em geral, as Pastorais da Juventude trabalham com a perspectiva da "opção preferencial pelos pobres" de caráter teológico-pastoral, mas também sociopolítico, produzindo um tipo de cultura juvenil com leve tendência à atuação extraeclesial a partir da comunidade católica (SOFIATI, 2012).

O quarto grupo, de atuação predominantemente intraeclesial, os carismáticos, é considerado como uma tendência modernizadora-conservadora. Os jovens desse setor atuam em grupos de oração, por exemplo. Mesmo não havendo grupos específicos para a juventude, há diversos que se preocupam com a evangelização juvenil e tratam de temas voltados para esse segmento. Há também forte presença juvenil nas Comunidades de Vida e Aliança: um caso importante é a Canção Nova, que define entre suas vocações a evangelização juvenil; outro exemplo é a Toca de Assis, que congrega majoritariamente jovens.

Como nos informam Carranza e Mariz, essas comunidades são formadas por "Leigos [que] decidem se reunir para se dedicar ao louvor, à adoração ao Santíssimo, à evangelização, à cura e às mais diversas obras sociais" (2016, p. 148). A cultura juvenil forjada entre os carismáticos é profundamente influenciada pela lógica de cultivo dos "carismas" e vivencia um catolicismo de cunho conservador em uma roupagem midiatizada que possibilita o diálogo com elementos da modernidade.

O que pretendemos ressalvar é que, mesmo no interior das quatro tendências apresentadas, há diferentes possibilidades e sentidos em ser 
católico, sendo, por isso, necessário acrescentar a perspectiva das culturas juvenis que identifica, inclusive, a fluidez das fronteiras entre as próprias tendências.

Ao analisarmos o caso das Pastorais daJuventude, encontramos diferentes concepções de atuação social, de formação comunitária e de evangelização de jovens. Por exemplo, a Pastoral da Juventude das comunidades, com atuação paroquial, e a Pastoral da Juventude do Meio Popular, com atuação nos movimentos sociais, se colocam em frontal oposição sobre as soluções para os principais problemas da juventude na medida em que a primeira valoriza a ideia de identidade juvenil e a outra, a noção de classe social.

A própria Pastoral da Juventude Marista, articulada nas escolas católicas das Congregações Maristas, possui um teor formativo/evangelizador inspirado nas Pastorais da Juventude. Identifica-se como promotora de uma evangelização que valoriza a "dimensão associativa" na vida dos jovens, em busca da "Civilização do Amor", que constrói a "consciência crítica" e solidária, em que o jovem atua na história para viabilizar um futuro com "mudança social"12.

Entre os carismáticos também há diferenças, por exemplo, entre os grupos de oração paroquiais e os grupos de oração universitários (SOFIATI, 2013). O debate neste caso se estabelece em relação ao grau de centralidade da sexualidade no discurso evangelizador. Nas paróquias há mais espaço para medidas coercitivas com relação à prática do sexo fora do casamento, diferentemente do contexto acadêmico no qual as liberdades individuais, entre elas a afetivo/sexual, hegemonizam o sentido das relações interpessoais. Ambos os grupos tendem a defender os princípios católicos de castidade, todavia, o tom é diferenciado entre esses dois grupos carismáticos.

A partir desses exemplos, consideramos que é importante analisar as culturas juvenis considerando a relação dessas com o meio social no qual estão inseridas. Atualmente o grupo com maior destaque no catolicismo contemporâneo, e pensando centralmente na juventude, são os carismáticos. Estes, inclusive, conseguem expandir suas práticas para outros grupos juvenis católicos: identificamos a influência carismática em grupos advindos dos Cursilhos de Cristandade, Treinamento de Lideranças

${ }^{12}$ Disponível em: <http:/ / pjm.maristas.org.br/a-pjm>. Acesso em 14 de abril de 2018. 
Cristãs, por exemplo, e até mesmo grupos de base das pastorais da juventude (SOFIATI, 2014; CARRANZA, 2015). Esse é um traço importante a ser destacado, considerando que estamos tratando de um cenário no qual a lógica da pentecostalização do cristianismo é uma realidade considerada neste estudo.

\section{Crentes e seculares: considerações}

Crentes e seculares, expressão paradoxal se assumirmos que a condição moderna traz a afirmação da autonomia individual, enquanto a Igreja Católica se propõe a discipliná-la por meio do alinhamento a uma visão de mundo nos moldes da verdade revelada, configurando subjetividades e comportamentos. A JMJ transforma-se então em palco no qual ressoam essas propostas, e as inúmeras atividades desenroladas operam como mecanismos que validam crenças e práticas religiosas e, por sua vez, acionam dispositivos de pertença institucional. Ainda que dita adesão não implique o alinhamento monolítico à visão de mundo da Igreja, como já dissemos.

Afirmamos que a juventude alinhada institucionalmente, como categoria analítica, nos auxilia na compreensão de tais dispositivos que permitem a jovens e grupos negociar com os ideais, propostos pela instância definidora, e as convicções seculares adquiridas pessoalmente. Juventude que perfila sua identidade no trafegar entre a catolicidade e uma consciência secularizada, essa última tida como um claro limite entre as opções pessoais e as demandas institucionais. Negociação que dispensa nos participantes sentimentos de culpa, sobretudo enquanto seu posicionamento sobre temas polêmicos, pois sua pertença à Igreja é associada ao legado tradicional mais amplo que oferece certa segurança, por os inserir num marco de normatividade cotidiana. São esses dispositivos de negociação que, nos termos de Berger, se constituem em atos de equilíbrio cognitivo, prototípicos da modernidade na juventude católica brasileira.

Rente a essa lógica, como foi apresentado nos posicionamentos dos pesquisados, os jovens alinhados institucionalmente em temáticas de cunho moral gravitam em torno do duas posturas. A do catolicismo liberal, quando assumem sua autonomia pessoal no uso de anticoncepcionais e a do catolicismo tradicional e conservador ao rejeitar o aborto, o sacerdócio casado, as relações sexuais e a convivência antes do casamento. Quando se trata de homossexualidade, papel da mulher, casamento homo-afetivo, 
os posicionamentos desses jovens tendem a não ser enfáticos, da mesma maneira que acontece nos diversos setores da Igreja e da sociedade.

Nessa clivagem, ao falarmos de juventude é preciso pensar o termo no plural, até mesmo para analisar grupos que participam de uma mesma instituição, como os jovens católicos. Em sua aparente unidade como jovens alinhados institucionalmente, o pesquisador reconhece a diversidade de culturas juvenis que surgem em virtude das origens sociais, mas também das perspectivas e aspirações dos próprios jovens com relação ao seu espaço de atuação sociorreligioso.

Sustentamos que a categorização de culturas juvenis permite refinar os referenciais e pressupostos a partir dos quais essa juventude alinhada institucionalmente negocia sua adesão à Igreja, se reconhece e insere ativamente nela. Assim, ao conter as culturas juvenis a juventude institucionalizada se constitui desse amplo espectro de jovens que concretizam a aspiração eclesiástica de promover uma Juventude católica, independentemente de seu grau de fidelidade doutrinal.

Enfim, retomamos o postulado sugerido por Berger acerca da visão secular e crente serem concomitantes à experiência religiosa contemporânea. Simultaneidade que observamos no pluralismo de posturas, tanto nos grupos quanto na própria crença dos participantes, manifestada em eventos públicos da natureza da JMJ. Revela-se então que as aspirações de (re) institucionalização, proposta pelos idealizadores das Jornadas não coincidem com as posturas de seus alvos, porém sua adesão com essas dissonâncias reforçam à instituição porque visibilizam uma adesão pública à igreja em outras posturas.

Distanciamo-nos assim, da perspectiva de Hervieu-Léger, para a qual a vivência da autonomia pessoal enfraqueceria a instituição católica. Menos longe nos localizamos de Camurça que, ao analisar dados sobre participantes da JMJ, reconhece que os laços orgânicos estabelecidos por jovens engajados na instituição reforçam a catolicidade, mas que essa identidade fica dúbia perante as exigências da Igreja católica a seus membros (Camurça, 2015, p. $23 ; 27)$.

Enquanto chaves analíticas para uma sociologia da juventude católica, sugerimos que na juventude alinhada institucionalmente, diversificada em culturas juvenis, os jovens experimentam sua autonomia pessoal e a adesão institucional como estanques não conflitantes. Isso que poderia ser uma fraqueza institucional se constitui numa força, visto que garantem, à sua maneira, a minguada capilaridade da Igreja católica entre as novas 
gerações.

Entretanto, se as culturas juvenis representam diferentes modelos de igreja dentre o grande guarda-chuvas em que se constitui o catolicismo, acreditamos que entre elas a cultura juvenil pentecostalizada tende a ser hegemônica. A energia mobilizadora dessa juventude possibilita a visibilidade social da Igreja católica que, de tempos em tempos, concretiza suas performances institucionais nas JMJ.

\section{Referências}

BERGER, Peter.

(2017). Os múltiplos altares da modernidade: rumo a um paradigma da religião numa época pluralista. Petrópolis: Vozes.

(2001). A dessecularização do mundo: uma visão global. In: Religião \& Sociedade, 21 (1), abr., ISER, p. 09-23.

BRANDÃO, Carlos R.

(2013). Catolicismo. Catolicismos? In Religiões em movimento: o CENSO de 2010. Rio de Janeiro: Vozes.

CAMURÇA, Marcelo Ayres.

(2015). Autonomia ou identificação orgânica entre a juventude católica e a instituição Igreja? Uma comparação entre estudos sobre as juventudes católicas no Brasil e na França. In: Péricles Andrade (Org.); Polifonia do Sagrado: pesquisas em Ciências da Religião no Brasil. São Cristóvão, Editora da Universidade Federal de Sergipe. p. 15-29.

CARRANZA, Brenda; MARIZ, Cecília.

(2016). Catolicismo brasileiro de exportação: o caso Canção Nova. In: A diáspora das religiões brasileiras. Aparecida, Ideias \& Letras. p. 149182.

(2014). Catolicismo brasileiro além fronteiras. In: Novas leituras do campo religioso brasileiro. Emerson José Sena da Silveira, Flávio Sofiati (Orgs.); Aparecida, Ideias \& Letras, p. 21-54.
CARRANZA, Brenda.

(2015). Cristianismo pentecostal: a nova face da Igreja católica. In: Alberto da Silva Moreira; Pino Lucà Trombetta (Orgs); Pentecostalismo globalizado. Goiania, Ed. da PUC-Goiás. p.7193.

(2013). A JMJ cristalizou a consagração da cultura gospel católica no Brasil. In: Papa Francisco no Brasil, alguns olhares. Cadernos de Teologia Pública. Ano VII, n.79, p. 31-37.

COSTA, Giovani Bernardo.

(2014). Catolicismo tradicionalista e Arautos do Evangelho: aspectos fundamentais de um tradicionalismo católico). Dissertação de Mestrado apresentada ao Programa de Pós-graduação em Ciências da Religião da Universidade de Juiz de Fora (UFJF).

DULLO, Eduardo.

(2016 ). Testemunho cristão e secular. In: Religião e Sociedade, RJ, n. 36, vol. 2. p. 85106.

GALLAND, Olivier.

(2009). Les jeunes. Paris, La Découverte.

KERBAUY, Maria Teresa.

(2005). Políticas de juventude: políticas públicas ou políticas governamentais? Estudos de Sociologia, Araraquara, 18/19. p. 193-203. 
MARIZ, Cecilia; CARRANZA, Brenda.

(2017). Francisco en la Jornada Mundial de la Juventud de Río de Janeiro. In: Francisco, el impacto de su pontificado en América Latina. Verónica Roldan; Alejandro Frigerio (Eds.), Buenos Aires, Editorial Biblos. p.71-88.

PAIS, José M.

(2006). Buscas de si: expressividades e identidades juvenis. In Culturas jovens: novos mapas do afeto. Rio de Janeiro, Jorge Zahar. p. 7-21.

(2003). Culturas juvenis. Lisboa, Imprensa Nacional Casa da Moeda.

DA SILVA, Isabela Oliveira Pereira

(2017). Gênero, política e religião nos protestos contra Judith Butler. Jornal eletrônico: Nexo Jornal, Ensaio, 21 de novembro de 2017. Disponivel em: https://www.nexojornal. com.br/ensaio/2017/G\%C3\%AAneropol\%C3\%ADtica-e-religi\%C3\%A3o-nosprotestos-contra-Judith-Butler. Acesso em 23 de março de 2018.

SOFIATI, Flávio M.

(2014). Ethnography of Catholic Youth Group: Dialogues and Experiences of Faith. Sociology Study, v. 4, p. 103-116.
(2013). Jovens católicos carismáticos nas universidades: a fé que pauta a ciência. In Perspectiva Teológica, maio/agosto, ano 45, número 126, Belo-Horizonte-MG. p. 179-204.

(2012). Juventude Católica: o novo discurso da Teologia da Libertação. São Carlos / Goiânia, EDUFSCar / CAJU.

(2011). Religião e juventude: os novos carismáticos. São Paulo, Ideias \& Letras / FAPESP.

VITAL-CUNHA, Christina; LOPES, Paulo Victor Leite; LUI, Janayna.

(2017). Religião e Política: medos sociais, extremismo religioso e as eleições 2014. Rio de Janeiro, Fundação Heinrich Böll / Instituto de Estudos da Religião.

\section{Recebido em}

abril de 2018

\section{Aprovado em}

setembro de 2018 